\title{
Discurso de Raúl Ricardo Alfonsín en el predio de Parque Norte de la Capital Federal, el $1^{\circ}$ de diciembre de $1985^{1}$
}

\author{
Ailén Díaz ${ }^{2}$ Universidad Nacional de La Plata \\ Revista Derechos en Acción \\ Año 3/No 9 Primavera 2018, 543-588 \\ DOl: https://doi.org/10.24215/25251678e242 \\ ORCID: https://orcid.org/0000-0001-8438-6622
}

El pasado 29 de octubre de 2018 se celebró el 35 aniversario de la vuelta de la Democracia en la República Argentina, fecha propicia para recordar el discurso del -por aquel entonces Presidente de la República Argentina- Ricardo Alfonsín al Comité Nacional de la UCR en diciembre de 1985, poco después de ganar las elecciones legislativas.

La transición entre el gobierno militar y el democrático no podía dejar de ser conflictivo, por lo que el gobierno radical tuvo el enorme desafío de retomar los valores democráticos, institucionales y fomentar la civilidad. Lo hizo apoyándose en la idea de la ética de la solidaridad, el pluralismo, la participación y la modernización.

El presente discurso que se transcribe resulta muy interesante en su contenido programático y en su definición ideológica. Interpela respecto a qué debe entenderse con 'democracia', y a

\footnotetext{
1 Desgrabación realizada en septiembre de 2018 por Nathalie Goldwaser Yankelevich (CONICET) a partir del audio sonoro de LRA1, Radio Nacional Argentina. La duración de dicho archivo es de 1 hora 42 minutos. Se debe un especial agradecimiento a Alberto Ronzoni y a Mariana Antoñanzas por proveernos del archivo resguardado. Asimismo, los editores de REDEA agradecen, también, al Prof. Leandro Abel Martinez de la Facultad de Derecho de la Universidad de Buenos Aires por su diligencia para conseguir el discurso.

2 Abogada, docente de la materia Historia Constitucional de la Facultad de Ciencias Jurídicas y Sociales de la Universidad Nacional de La Plata.
} 
generar diálogos o acuerdos para la construcción del país. Posee una génesis de pensamiento popular y progresista, anclado en una reforma cultural, institucional -con mayor participación ciudadana y mayor injerencia de los partidos políticos-, y dentro de la propuesta económica, modernizando al país no solo desde el punto de la eficiencia sino también de la función social que cumple dicha modernización.

Se vertebra en el mentado discurso, un proyecto de país en transición, una forma de superación a las atrocidades económicas, sociales y políticas acontecidas durante la última dictadura cívica-militar.

En este acto político, Alfonsín plasma el proyecto democrático que aspira; es un proyecto donde valores de modernización se entrelazan con los éticos, con los cambios sociales, culturales y políticos. Y sabe que dichos procesos no se hacen sin discusiones y divergencias, por lo tanto fomenta la idea del pluralismo como un fuerte valor de la democracia y como un mecanismo para la adopción de decisiones que suponen asumir como legítimos el disenso y el conflicto. Asimismo establece que para el adecuado funcionamiento de las reglas de juego democráticas, el Estado debe funcionar como canalizador y promotor de la participación de los ciudadanos, pues entiende que "no hay sociedad democrática sin disenso, ni tampoco sin reglas de juego compartidas, y menos sin participación ciudadana". De tal forma que el discurso político debe ayudar a que las rutinas democráticas sean hábitos queridos y compartidos por la ciudadanía.

La sociedad del futuro a la que se refiere el líder radical, se basa sobre el ejercicio pleno de los derechos de los ciudadanos, las libertades individuales y la solidaridad social. Los nuevos valores, la tolerancia, la racionalidad, el respeto y la búsqueda de soluciones pacíficas a los conflictos hacen posible un tránsito de la sociedad autoritaria a la sociedad democrática. La idea entonces es pasar de la vieja política de puertas cerradas a la nueva política en contacto directo con las demandas y propuestas del pueblo. 
Se trata de sustituir la violencia y la intolerancia por la discusión y el pluralismo, la exclusión de la lucha salvaje, reemplazándola por el debate abierto y el respeto a la decisión mayoritaria y los derechos de las minorías.

A criterio de Alfonsín, "la sociedad argentina ha sido una sociedad fuertemente influida por el egoísmo de las clases dirigentes, y ese egoísmo ha debilitado la solidaridad social, generando situaciones de desamparo y miedo. Por lo que es fundamental una ÉTICA DE LA SOLIDARIDAD, lo que implica que la sociedad sea mirada desde el punto de vista de quien está en desventaja en la distribución de talentos y riquezas. Un pacto democrático basado en esta ética de la solidaridad supone la decidida voluntad de que esté sustentado en condiciones que aseguren la mayor justicia social posible, y consecuentemente reconoce la necesidad de apoyo de los más desfavorecidos".

En otro orden de ideas, se refiere a la inserción de la República Argentina en el contexto internacional, así afirma que la integración latinoamericana será un paso necesario y valioso.

La integración desde lo económico se traslucirá proclamando la injusticia de pueblos ricos y pueblos pobres, de las prácticas discriminatorias de los países desarrollados, inadmisibles desde el punto de vista ético e insostenibles para las naciones que profesan la democracia y la libertad como valores orientadores de su organización interna.

La construcción de un país moderno y desarrollado, integrado digna y creativamente al sistema económico internacional a través de la integración regional, deberá concretarse con las fuerzas de todos los sectores de la sociedad, con el fin de ponerle freno al orden económico internacional imperante, que por su injusticia que no es a la larga sostenible.

Podemos ver como estas palabras, hoy 35 años después siguen estando vigentes, con un sistema financiero internacional voraz que no para de hacer estragos en los pueblos del mundo, urge su modificación, ya lo veía Alfonsín; en la actualidad aún resta propender por un sistema internacional más justo. 
El proyecto que comentamos, se basa en la idea de un proceso de modernización que tienda progresivamente a incrementar el bienestar general de modo que la sociedad en su conjunto pueda beneficiarse de sus frutos. Pero como es sabido, no es fácil conciliar armoniosamente la eficiencia con la justicia. Este interés en modernizar sin perder de vista los valores éticos de la sociedad, fundamentalmente la justicia social deben llamarnos a la reflexión, pues en la actualidad el gobierno macrista apuesta a las fachadas modernizantes, desatendiendo las necesidades reales de la población. Una aparente 'eficiencia estatal', a modo de desarrollo e implementación nuevos sistemas informáticos, no siempre se traduce en la resolución de las demandas de la sociedad.

Con mucho acierto, a nuestro criterio, Alfonsín ve la necesidad de revertir el proceso de centralización en la administración estatal, la cual debe orientarse con el fin de asegurar a la población las posibilidades más amplias de participación. Así, "una gestión estatal muy concentrada implica confiar el manejo de la cosa pública a un núcleo burocratizado de la población, que desarrolla como tal, conductas sujetas en mayor medida a sus propios intereses corporativos que al interés general de la población".

No queriendo explayarnos en demasía, e invitarlos a su lectura, queremos destacar que este extenso discurso, con gran contenido de valores, finaliza con una convocatoria a todos aquellos que deseen sumarse al proyecto propugnado, en busca de una sociedad más justa y vertebrada en lógicas democráticas. La propuesta de este gran estadista es entonces, modernizar a través de la integración de todo el pueblo, orientando a que sea la propia sociedad la que construya su futuro. E insiste una vez más, "sin solidaridad no se construye ninguna sociedad estable y el primer deber que nos impone la ética de la solidaridad es incorporar al trabajo común todo aquellos que, sin renegar de su historia se sientan convocados en un proyecto como el que hemos definido". 


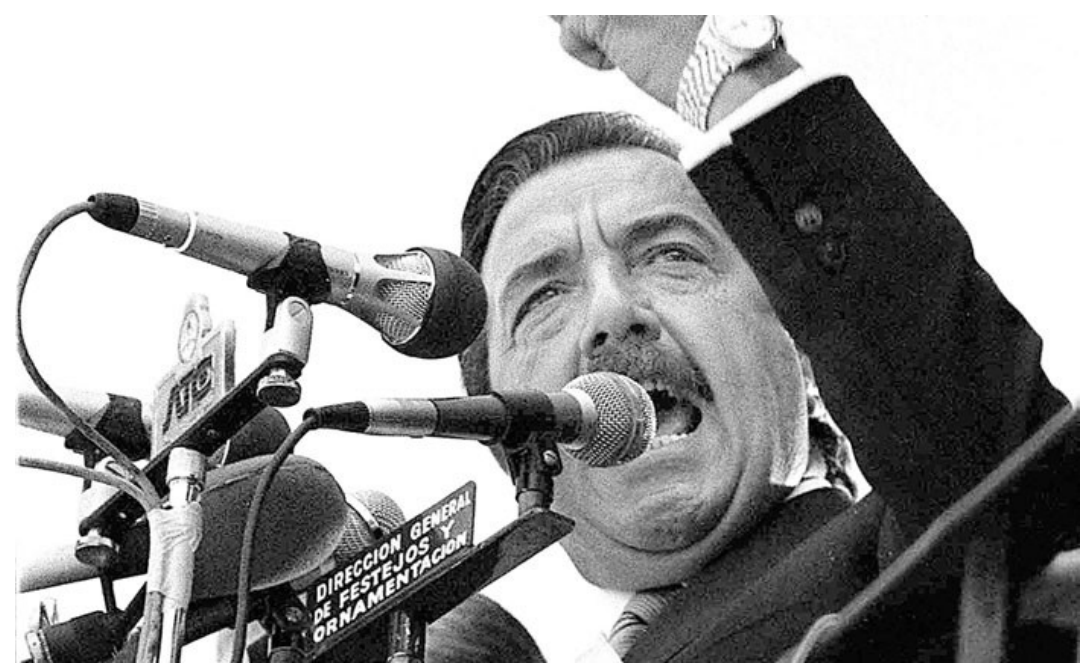

Señor presidente del Comité Nacional, Señores delegados:

A través de los dos años de gobierno, en actitud que ha de continuar durante toda mi gestión, he procurado en todo sentido, no sólo ser, sino también parecer el presidente de todos los argentinos. Es por eso que esta es la primera oportunidad en la que tengo el gusto y la alegría de encontrarme con ustedes.

Diría yo que es una excepción que confirma la regla, en un doble sentido: en primer lugar, por la excepcionalidad misma. $\mathrm{Y}$, en segundo lugar, porque hemos de llamar al país para una acción. Y dentro del país, desde luego, incluimos a la Unión Cívica Radical. Y pensamos que, sin su determinación, sin su apoyo, sin su convicción, esta convocatoria no podría en realidad concretarse.

Hemos llamado a este trabajo: "Convocatoria para una convergencia democrática”.

El desafío.

La Argentina afronta la necesidad de construir un futuro capaz de sacarla de largos años de decadencia y de frustraciones. Como sociedad, se encuentra en una de las más serias encrucijadas de su historia. En las vísperas del siglo XXI, y en 
medio de una verdadera mutación civilizatoria a escala mundial, deberá decidir si ingresará a ese proceso como protagonista, o como furgón de cola de las grandes potencias hegemónicas.

La lógica del poder en el mundo del futuro, no perdonará a quienes abdiquen de la voluntad de autodeterminarse. Sin aspirar ilusoriamente a constituirse en una potencia mundial, la Argentina como sociedad dotada de riquezas naturales y humanas considerables, puede y debe aspirar a desempeñar un papel significativo en este profundo proceso de transición que vive la Humanidad, tan crucial y dramático como lo fueron hace dos siglos la Revolución Industrial y la Revolución Democrática, que abrieron nuevos horizontes para la historia de Occidente y de la humanidad toda.

¿Cómo hacerlo? ¿Sobre cuáles bases definir nuestro posible futuro? ¿En qué marco colocar nuestra voluntad de transformación? Acometer una empresa colectiva no es tarea simple. Implica una movilización de energías que abarca no sólo a la dirección política de la sociedad, es decir, al Estado y al sistema político, sino también a los grupos y a los individuos para que, sin renunciar a la defensa de sus intereses legítimos, sean capaces de articularlos en una fórmula de solidaridad.

El futuro es siempre deudor de voluntades, de actores, de entusiasmo y de inteligencia colectiva. No hay empresa nacional sin pueblo, y no hay pueblo sin personas conscientes de que su vida cotidiana forma parte de la vida de la comunidad. Frente al fracaso y al estancamiento, venimos a proponer hoy, el camino de la modernización.

Pero no lo queremos transitar sacrificando los valores permanentes de la ética. Afirmaremos que sólo la democracia hace posible la conjugación de ambas exigencias. Una democracia solidaria, participativa y eficaz, capaz de impulsar las energías, de poner en tensión las fuerzas acumuladas en la sociedad.

Combinar la dimensión de la modernización con el reclamo ético, dentro del proceso de construcción de una democracia estable, implica la articulación de una serie de valores que se 
redefinen en su interacción, puesto que la modernización es calificada por sus contenidos éticos y la ética lo es por el proceso de modernización.

¿Cuáles son esos valores sobre los que aspiramos a constituir las rutinas de una sociedad democrática? Pensamos que una sociedad democrática se distingue por el papel definitorio que le otorga el pluralismo, entendido como un valor antes que como un procedimiento para la toma de decisiones. En estos términos, el pluralismo es la base sobre la que se erige la democracia, y significa reconocimiento del otro, capacidad para aceptar las diversidades y discrepancias como condición para la existencia de una sociedad libre. La democracia rechaza un mundo de semejanzas y uniformidades, que en cambio forma la trama íntima de los totalitarismos. Pero este rechazo de la uniformidad, de la unanimidad, de ninguna manera supone la exaltación del individualismo egoísta, de la incapacidad para la construcción de empresas colectivas.

La democracia sólo puede constituirse a partir de una ética de la solidaridad capaz de vertebrar procesos de cooperación que concurran al bien común. La ética de la democracia se basa en una idea de la justicia como equidad, como distribución de las ventajas y de los sacrificios, con arreglo al criterio de dar prioridad a los desfavorecidos, aumentando relativamente su cuota de ventajas y procurando disminuir su cuota de sacrificios. La modernización que se impulsa no puede estar al margen de estos reclamos éticos.

Construir una sociedad democrática moderna, y fundada en una ética de la equidad y la solidaridad, requiere afrontar con decisión y solvencia los problemas que plantea la permanente tensión entre el orden y el cambio social. Una antigua concepción, generalmente asociada a las derechas tradicionales, tiende a juzgar al orden social como un valor absoluto y suficiente, y a calificar al disenso y, sobre todo, al conflicto como eventualidades negativas e indeseables por principio.

Otra concepción, no menos añeja, vinculada a ciertas izquierdas exalta, en cambio, las presuntas virtudes de la lucha 
y el antagonismo constantes, considerando como perniciosa toda estrategia que se preocupe por la construcción de un orden político estable.

Superar esta falsa disyuntiva constituye uno de los principales desafíos de la democracia. Por cierto, un proyecto democrático que afirme resueltamente los valores de la modernización es, por definición, un proyecto de cambio social, económico, político, cultural. Y es sabido que los procesos de cambio en sociedades complejas como la Argentina dan lugar, y es bueno que así sea, a discusiones, divergencias y conflictos respecto de las formas de implementación y de los mismos objetivos.

Aquí es preciso rescatar nuevamente la idea de pluralismo entendida, no sólo como uno de los valores fundantes de la democracia, sino también como mecanismo de funcionamiento político o, más precisamente, como un procedimiento para la adopción de decisiones que supone asumir como legítimos, el disenso y el conflicto.

La reivindicación del disenso es válida en tanto pone al descubierto los riesgos inherentes a los pretendidos valores de la unanimidad y la uniformidad. Ello, sin embargo, no nos debe llevar a una suerte de neo-anarquismo ingenuo que rehabilite al conflicto permanente y descontrolado como una presunta virtud democrática.

El ejercicio responsable de las divergencias y las oposiciones, supone un consenso básico entre los actores sociales, esto es, la aceptación de un sistema de reglas de juego compartidas. El disenso democrático implica, pues, como condición de su ejercicio, un orden democrático. Pero este orden democrático no debe ser concebido, exclusivamente, como un límite a las iniciativas de los actores políticos individuales y colectivos. Por el contrario, dicho orden debe definir las modalidades legítimas positivas de la participación política. $\mathrm{O}$, si se quiere, promover e instaurar una relación de reciprocidad en virtud de la cual los actores, al tiempo que se avienen a compartir una normativa 
común; adquieren el derecho y la responsabilidad de intervenir activamente en la adopción de las decisiones políticas.

Como garante del adecuado funcionamiento de las reglas de juego democráticas, y como canalizador y promotor de la participación de los ciudadanos, el papel del Estado es fundamental. Particularmente, en una etapa de transición y consolidación democrática como la que vive nuestra sociedad. No hay sociedad democrática sin disenso, no la hay tampoco sin reglas de juego compartidas, ni la hay sin participación. Pero no hay, además, ni disenso, ni reglas de juego, ni participación sin sujetos democráticos.

¿Qué es un sujeto democrático? Simplemente aquel que ha interiorizado, hecho suyos los valores éticos y políticos antes expuestos: legitimidad del disenso, pluralismo como principio y como método, aceptación de las reglas básicas de la convivencia social, respeto de las diferencias, voluntad de participación.

En un país con arraigadas tradiciones autoritarias, la emergencia de sujetos democráticos no va de suyo: es una tarea, es una empresa. Desde el punto de vista de los individuos es, a su vez, un aprendizaje producto de experiencias, de ensayos y errores, de frustraciones y gratificaciones. Durante años, ha sido un aprendizaje solitario y desvalido.

El Estado democrático debe contribuir decisivamente a consolidar y acelerar ese aprendizaje. El discurso político debe, en tal sentido, ayudar a que las rutinas democráticas se conviertan en hábitos queridos y compartidos por la ciudadanía. Corresponde también, a los partidos políticos, promover la voluntad de democratización de la sociedad toda, operando como verdaderas escuelas de civismo. A este empeño, debe sumarse las organizaciones representativas de las distintas franjas del quehacer colectivo, tanto en lo económico como en lo cultural y lo espiritual.

No menos importante será la función del sistema educacional y de los medios de comunicación que deberán asumir la creciente cuota de responsabilidad que les corresponde en una sociedad moderna. 


\section{Las condiciones:}

La construcción de una sociedad diferente.

Se requiere construir una sociedad diferente. Anteriores intentos de cambio de la estructura social y económica del país, fueron concebidas como políticas elitistas que excluyeron la participación de los ciudadanos en las decisiones atinentes a su futuro. Pero hoy se ha producido en la Argentina la toma de conciencia de una sociedad que asume como propia la responsabilidad de decidir su destino, de elaborar consensualmente su proyecto de país.

El primer paso concreto para la construcción de una sociedad diferente, de una sociedad mejor, es esta apertura de compuertas que convierte a la vieja sociedad cerrada, en una sociedad abierta y plural. El ejercicio pleno de los derechos ciudadanos, las libertades individuales y la solidaridad social, constituyen la base sobre la que se empieza a levantar el edificio de la sociedad moderna. Los nuevos valores de la comunidad argentina, la tolerancia, la racionalidad, el respeto y la búsqueda de soluciones pacíficas a los conflictos, hacen posible un tránsito sin traumas de la sociedad autoritaria a la sociedad democrática.

En esta nueva sociedad, cada argentino debe sentir que posee poder de opinión, poder de decisión y poder de construcción.

Lo debe sentir y debe estar en condiciones de ejercerlo activamente. Esto significa sumar a los derechos formales, inscriptos en nuestro texto constitucional, derechos reales, ampliar los canales de comunicación social, estrechar los lazos de interrelación entre las personas, pasar de la macro política a la acción comunitaria para el debate y la solución de problemas concretos, acercar canales de participación a la sociedad, pasar de la vieja política de puertas cerradas a la nueva política en contacto directo con las demandas y propuestas del pueblo. La política, debe quebrar la barrera de la frialdad y la lejanía con la cual la observan muchos argentinos. 
La sociedad nueva que nace, consolidará las conductas integradoras y solidarias expresadas en actitudes de cooperación y predisposición al cambio superador y al progreso; por oposición a las conductas agresivas y al individualismo egoísta que bloqueó a la sociedad y anuló la iniciativa.

La construcción de una sociedad diferente es un inmenso desafío: requiere escapar de las pujas salvajes y de la lucha de todos contra todos, a través de un pacto social entre los actores. Pero ese pacto sólo puede lograrse de verdad, cuando un gran objetivo nacional lo exige y lo legitima. El compromiso común para la construcción de una sociedad mejor es, entonces, la sustancia misma del pacto social. Y la acción conjunta para hacerla realidad y consolidarla será la condición de su vigencia y de su éxito.

La transición en libertad hacia la nueva sociedad implica de por sí una concepción del país que se quiere, con una sociedad integrada y una interdependencia y comunicación más estrecha entre los hombres que garantice un común universo de valores compartidos y un orden respetado por todos. Lograr la consolidación de esta sociedad integrada, supone contener en un marco de convivencia, los antagonismos que en el pasado nos dividieron y poner fin a las luchas que nos desgarraron.

La sustitución de la violencia y la intolerancia por la discusión y el pluralismo, la exclusión de la lucha salvaje como medio para dirimir las naturales contiendas entre diferentes ideas y propuestas, y su reemplazo por el debate abierto y el consecuente respeto a la decisión mayoritaria y a los derechos de las minorías constituyen un primer compromiso para la movilización detrás de objetivos comunes.

La sociedad nueva que veremos crecer, como fruto de la concreción de los anhelos y las esperanzas del pueblo, no es otra que una sociedad verdaderamente democrática hecha por y para el hombre de nuestra patria. Su fin será facilitar a todos sus miembros, el logro de su destino individual y social, perfeccionándose en la armonía y la originalidad de todas sus aptitudes, fuerzas y tendencias. 
La sociedad no debe ni va a pesar, pues, sobre el hombre, sino que debe y va a facilitar su desarrollo y el despliegue de sus potencialidades, así como el de sus derechos imprescriptibles: el derecho a la vida, al trabajo, a la educación, a la libertad, a la igualdad, a la propiedad en función social, y a la participación activa y responsable en las decisiones políticas, así como en la generación y distribución equitativa de la riqueza.

El cambio que vamos a emprender no es un fin en sí mismo, sino que tiene como uno de sus objetivos centrales la construcción colectiva de una sociedad diferente, que dé sentido afirmativo y liberador a la convivencia nueva que se inicia entre los argentinos.

Conquista de un lugar para la Argentina en el mundo.

Es menester también lograr una correcta inserción de la Argentina en el mundo. Esta cuestión en el contexto mundial contemporáneo representa un problema global que nuestro país debe enfrentar desde la perspectiva de su propio cambio interno hacia la modernización y la consolidación de la democracia, y en adecuada relación con los cambios que se están produciendo en las otras naciones y en sus relaciones entre sí, y con las distintas áreas regionales, políticas, militares y económicas.

Para encarar el tema con mayor eficacia, es conveniente desglosar la cuestión global en los siguientes niveles: inserción política, inserción cultural, inserción económica e inserción estratégico-militar. Dentro de cada uno de esos niveles, corresponderá distinguir los grados y etapas de inserción tanto en lo espacial como en lo temporal.

Inserción política:

La Argentina por tradición y vocación se adscribe al conjunto de las naciones que postulan la democracia pluralista como el sistema político más justo, más eficaz y más conveniente para la organización y el gobierno de las sociedades modernas y complejas.

Ello no implica la supeditación a ningún grupo de naciones, sino la subordinación doctrinaria a un principio que consagra al sistema de partidos políticos como factor esencial de una 
democracia efectiva, con pleno respeto por los derechos a la oposición y al disenso, y con la alternancia como posibilidad siempre abierta.

En este marco, y en el respeto a los principios de no intervención y autodeterminación, la Argentina debe bregar por la consolidación de sistemas análogos en el subcontinente latinoamericano, entendiendo que la democracia no puede ser el privilegio de algunas pocas naciones.

Asimismo, propenderá a que las reglas democráticas sean también el patrón que guíe las relaciones entre las distintas naciones del mundo y sus agrupamientos regionales, históricos y culturales.

La Argentina renovada asumirá para sí y propondrá para el resto de los pueblos del mundo, un concepto también renovado de la democracia, que intensifique su carácter participativo, y extienda y profundice las instancias de intervención de los ciudadanos en la adopción de las reglas y en la toma de las decisiones.

La integración política latinoamericana será considerada como un paso necesario y valioso de por sí, que deberá tender hacia un futuro en el que la humanidad en su conjunto comparta los avances científicos, tecnológicos, económicos y culturales de esta etapa de modificaciones profundas en la organización de las sociedades. Ya se ha dicho que la Humanidad es el conjunto de los seres que se influyen recíprocamente en forma incesante y se vinculan con Dios en la búsqueda de la unidad suprema.

La plena vigencia de los derechos humanos será un valor fundamental, tanto en lo interno como en lo internacional, y para su defensa no se admitirán barreras geográficas o ideológicas de ningún tipo.

En este terreno no hay injerencias indebidas. Se trata del valor supremo y del patrimonio indivisible de toda la Humanidad.

Inserción cultural:

Por tradición y por vocación, la Argentina pertenece a un ámbito específico en el contexto de la cultura mundial. Es aquél que recibimos, asumimos y enriquecimos por la incorporación de nuestro continente a la civilización europea. 
De allí provienen nuestros valores políticos, pero igualmente comportamientos colectivos, modalidades de vida, concepciones científicas y estéticas, y sus consiguientes prácticas.

Ese incuestionable legado se amalgamó en Latinoamérica, con mayor o menor grado de intensidad según los casos, con las precedentes culturas autóctonas que, en nuestra integración nacional y regional, no pueden quedar ignoradas.

Como en lo político, la libertad es valor esencial en lo cultural, y en tal sentido la Argentina debe ser una celosa defensora de las libertades de pensamiento, de religión, de creación y de investigación, con pleno respeto y tolerancia por los pueblos que provienen de otras tradiciones.

Consideramos que el intercambio fecundo entre todos los pueblos dará lugar, en un futuro no muy lejano, a mayores cuotas de integración en una cultura universal, que los modernos sistemas de comunicación, y los otros tipos de relaciones entre los pueblos tornan inevitable y deseable, sin desmedro de las identidades locales, nacionales y regionales.

La Argentina, por lo tanto, no debe admitir obstáculos ni restricciones al intercambio cultural entre los pueblos, ni a la libre difusión de las ideas, al margen de los sistemas políticos y económicos. Debe abrir sus puertas a la producción cultural del mundo y exigir una análoga posibilidad para sí.

Inserción económica:

La Argentina no puede admitir una división económica del mundo entre centro y periferia, entre Norte desarrollado y Sur subdesarrollado, como realidad inmodificable. Sostiene, por el contrario, que la persistencia o el incremento de tal situación derivará en conflictos y tensiones que pondrán en peligro la misma prosperidad y seguridad de los países desarrollados y centrales.

No basa esta posición en una simple comprobación práctica o estratégica. Proclamará, en cambio, la injusticia de la existencia de pueblos ricos y pueblos pobres, y de las prácticas discriminatorias de los países desarrollados, inadmisibles desde el punto de vista ético e insostenibles para las naciones que 
profesan la democracia y la libertad como valores orientadores de su organización interna.

Agotado el modelo de país agro-importador y superada la etapa de la sustitución de importaciones, la Argentina debe proponerse un proyecto de desarrollo que le permita escapar, tanto de la marginalidad, como del criterio de la complementariedad subordinada.

La profunda brecha tecnológica que la separa de los países más avanzados, y de otros nuevos polos de desarrollo que están surgiendo en la Cuenca del Pacífico, debe ser superada mediante una incorporación racional de modernos sistemas de producción, información y organización de la economía, en el marco de la integración latinoamericana que le otorgue más vastas áreas geográficas y poblacionales para el desarrollo del subcontinente.

Este proyecto de construcción de un país moderno y desarrollado, integrado digna y creativamente al sistema económico internacional a través de la integración regional, no será obra de un gobierno ni de un partido, ni podrá ser impuesto desde el Estado. A su concreción deben concurrir todos los sectores de la sociedad para evitar que continúe un proceso de deterioro caracterizado por un orden económico internacional injusto que no es, a la larga, sostenible.

La necesidad de modificación, no sólo debe ser impulsada por los países relegados, sino que además debe ser admitida como una necesidad ética, práctica y política por los países adelantados. No queremos ser los nuevos bárbaros en las fronteras de un nuevo imperio, pero los imperios deben recordar y meditar sobre cómo han terminado las historias con los bárbaros.

Tenemos la voluntad de participar, creadora y activamente, en la construcción de una humanidad mejor, más equitativa y más libre. No renunciaremos a ese derecho y lo defenderemos para todos los pueblos del mundo.

Inserción estratégico-militar: 
La Argentina no pertenece ni debe aspirar a pertenecer a ninguno de los dos grandes bloques militares que controlan una buena parte del mundo.

Debe considerar la existencia de dichos bloques como un peligro permanente para la paz mundial y apoyar todas las iniciativas tendientes al desarme. La Argentina tampoco debe aceptar que las divergencias entre los dos grandes bloques se diriman en escenarios bélicos y políticos de lo que se ha dado en llamar el Tercer Mundo y mucho menos aceptar para sí tal posibilidad.

Deberá condenar enérgicamente ese tipo de intervenciones y denunciar con el mismo vigor, la situación de naciones y pueblos al borde de la desintegración en virtud de injerencias externas que han exacerbado conflictos locales hasta convertirlos en guerras sin triunfadores posibles. Esta concepción, por otra parte, fundamenta su adhesión a los países "No Alineados", cuya independencia de los dos bloques debe ser preservada y respetada integralmente por todos los miembros, sin falsas especulaciones ni dobles juegos.

El "Movimiento de No Alineados" no debe constituir un tercer bloque, ni sostener posiciones ideológicas específicas. Sus objetivos fundamentales deben ser la paz, la justicia, la independencia y la convivencia entre todos los pueblos.

Asimismo, debe sostener que la posesión de tremendos arsenales nucleares por parte de las grandes potencias no es una cuestión que concierna solamente a ellas. Un eventual conflicto bélico con el empleo de armas nucleares implicaría la destrucción de la Humanidad toda, y la Humanidad toda debe tener voz y voto en las discusiones para conjurar tan terrible y definitiva amenaza.

Un cambio en la mentalidad colectiva:

El esfuerzo para crear bases estables para la convivencia democrática en la Argentina debe pasar necesariamente por una reforma cultural que remueva el cúmulo de deformaciones asentadas en la mentalidad colectiva del país como herencia de un pasado signado por la disgregación. 
El autoritarismo, la intolerancia, la violencia, el maniqueísmo, la compartimentación de la sociedad, la concepción del orden como imposición y del conflicto como perturbación antinatural del orden, la indisponibilidad para el diálogo, negociación, acuerdo o el compromiso, son maneras de ser y de pensar que han echado raíces a lo largo de las generaciones a partir de una histórica incapacidad nacional para la integración. Toda nación es el resultado de un proceso histórico integrador de grupos inicialmente desarticulados.

Detrás de cada unidad nacional hay un gran proyecto capaz de asociar en la construcción de un futuro común a fuerzas étnica, religiosa, cultural, lingüística o socialmente diferenciadas entre sí y provenientes, en general, de un pasado de disgregación. Uno de los rasgos distintivos de la Argentina ha sido nuestra ineptitud para delinear con éxito una empresa nacional de esta naturaleza. Un proyecto de país en el que todos los componentes de nuestra sociedad se reconocieran a sí mismos.

Otros países, conocieron en el pasado terribles luchas internas, pero supieron disolver sus dicotomías en unidades nacionales integradas, cuyos componentes se reconocen entre sí como parte del conjunto en un universo de principios, normas, fines y valores comunes.

Esta integración, aunque intentada varias veces, nunca alcanzó a prosperar en la Argentina, que mantuvo como una constante a lo largo de todo su itinerario histórico la división maniquea de su propia sociedad en universos político-culturales inconexos e inconciliables.

Nuestra historia no es la de un proceso unificador, sino la de una dicotomía cristalizada que se fue manteniendo básicamente igual a sí misma, bajo sucesivas variaciones de denominación, consistencia social e ideología.

Ahí están, como expresiones de esta división, los enfrentamientos entre unitarios y federales, entre la "Causa" yrigoyenista y el "Régimen", entre el conservadorismo restaurado en 1930 y el radicalismo proscripto, entre el peronismo y el antiperonismo. 
Bajo signos cambiantes, el país permanecía invariablemente dividido en compartimentos estancos que, en mayor o menor medida, se concebían a sí mismos como encarnaciones del todo nacional, con exclusión de los demás.

La Argentina no era una gran patria común, sino una conflictiva yuxtaposición de una patria y una anti-patria; una nación y una anti-nación. Como unidad política y territorial, la nación se asentaba en el precario dominio de un grupo sobre los demás y no en una deseada articulación de todos en un sistema común de convivencia.

Con el desarrollo económico, el país fue creciendo en complejidad, generando en su sociedad una progresiva diferenciación interna entre grupos políticos, corporativos y sectoriales, todos los cuales se tiñeron de aquella mentalidad animada por una conciencia cultural cerrada.

La Argentina ingresa a la segunda mitad del siglo XX con partidos compartimentados, organizaciones sindicales compartimentadas, asociaciones empresarias compartimentadas, fuerzas armadas compartimentadas, unidades culturalmente dispersas que sólo ocasionalmente se asociaban en parcialidades mayores, también excluyentes entre sí, pero nunca en esquemas de convivencia global.

En estos procesos de asociación, lo que se unía nunca era el país, sino un conglomerado interno que sólo lograba cifrar su propia unidad en la visualización del resto del país como enemigo. Este esquema, tuvo sus inevitables derivaciones en la mentalidad colectiva de los argentinos.

De él emanaron: el autoritarismo como forma natural de relación entre grupos que no concebían otro modo de coexistir que el de la imposición de unos sobre otros; la violencia como forma natural de interacción entre grupos que no reconocían la existencia de espacios normativos, axiológicos o finalísticos comunes.

La intolerancia como producto de una percepción también compartimentada de los valores. Cada grupo vivía bajo una constelación de valores percibida como una exclusividad propia e irreconocible en los demás. 
La ineptitud para la negociación, el acuerdo, el compromiso.

En una sociedad maniquea, cada grupo asigna un carácter absoluto a sus propios objetivos, y no puede considerar satisfactorio para sí un destino plasmado en la concesión, la conciliación negociada de los propios intereses con los de los otros grupos.

La Argentina ha sido siempre un país donde la intransigencia, más allá de la necesaria para preservar principios, era considerada una virtud. Donde la expresión "no transar" se multiplicó en lemas de los más variados signos y donde "negociar" era considerado una traición o una claudicación indecorosa.

La concepción del orden como imposición y del conflicto como desorden. En una sociedad culturalmente desarticulada, que no reconoce la existencia de espacios normativos comunes entre sus grupos componentes, el orden sólo resulta concebible como producto de una acción coercitiva -y por lo tanto básicamente represiva- del grupo dominante. A la luz de esta concepción, las situaciones de conflicto son vistas como una quiebra antinatural del orden, como algo que debe ser reprimido.

De más está decir que todas estas propensiones y actitudes componen cabalmente el cuadro de una mentalidad colectiva poco receptiva para la democracia. De ahí también, que la debilidad de la democracia en la Argentina, la precariedad y la fugacidad de los esfuerzos desplegados hasta ahora por consolidarla, radiquen menos en sus instituciones, que en nuestro modo subjetivo de asumirlas. Se trata de un problema cultural más que institucional.

Puede decirse que todos los intentos de revivir la democracia, habidos hasta ahora en el último medio siglo han fracasado, en gran medida, porque se encaraba la tarea simplemente como un modo de manipular situaciones objetivas, desatendiendo la mentalidad, la interioridad cultural de la gente.

Se daba por sentado que las expectativas naturales de todos, o la inmensa mayoría de los argentinos, eran democráticas y que, si resultaban frustradas por el devenir histórico concreto 
del país, era porque factores invariablemente exteriores a la mentalidad popular imponían por la fuerza soluciones antidemocráticas. Luchar por la democracia era siempre luchar contra otros. El enemigo estaba afuera y nunca dentro de nosotros.

En diciembre de 1983 se inicia por primera vez un esfuerzo de democratización basado en la conciencia de que la clave de los pasados regímenes autoritarios residía, menos en la fuerza intrínseca de los mismos, que en las posibilidades que tenían de asentarse sobre una cultura política general, disponible para aceptarlo.

Para nosotros, defender y consolidar la democracia significa luchar, no sólo contra fuerzas antidemocráticas objetivas, sino también contra las deformaciones culturales generadoras de aquella difundida disponibilidad subjetiva que les ha servido siempre de base de sustentación. En esta labor de democratización subjetiva, desempeñan un papel de enorme importancia los educadores, los periodistas, los dirigentes de las organizaciones sociales y representativas y los responsables de todos los medios de comunicación masiva.

Los caminos.

Proponemos una acción basada en un trípode fundamental: participación, modernización y ética de la solidaridad.

Una democracia participativa:

Heredamos un país que marginó de una vida social plena a los argentinos. Frente a un mundo agresivo donde reinaban la violencia, la desconfianza, la desunión y la indiferencia, los argentinos se habían acostumbrado a defenderse buscando refugio en la privacidad de los ámbitos más cercanos a su vida cotidiana, a su familia, a la sociedad de sus propios esfuerzos, al aquí y ahora, más que a un futuro que visualizaban como incierto.

De esta manera se redujo el espacio social en el cual transcurría la vida, y así se fueron perdiendo formas de unión y solidaridad tradicionales de nuestro país. Así desapareció la alegría del contacto humano y de la solidaridad fraterna. 
Al vaciamiento económico, le siguió el vaciamiento afectivo en una sociedad donde primaba el desamparo. La democracia comenzó a sentar las bases para revertir esta situación de encierro en que vivía el conjunto de nuestro pueblo, pero más especialmente los desposeídos y la juventud.

La libertad, la paz, la lucha contra la inflación, la legalidad, fueron los presupuestos básicos que aseguraron al argentino la tranquilidad mínima en esos ámbitos más cercanos a los cuales había sido reducida su vida. Pero además comenzaron a conformarse las condiciones de seguridad y normalidad necesarias para que las fronteras de la vida cotidiana empezaran a extenderse en dirección de la solidaridad y la participación social.

Ahora los argentinos, al par que encuentran su propio lugar, comienzan a conocer el del otro. $\mathrm{Y}$ en este doble movimiento, de encontrar su lugar y reconocer el lugar del otro, se afirma la esencia de la democracia y se posibilita la participación.

La participación es un movimiento destinado a agrandar los espacios de libertad, de bienestar y de relación humana. No puede ser impuesto desde factores externos a la vida misma de quienes participan, pero necesita del estímulo y del apoyo del conjunto de las instituciones públicas y privadas.

Es un movimiento que provoca cambios en la mentalidad colectiva y, consecuentemente, en las instituciones. Estos cambios están dirigidos a promover la integración de los argentinos entre sí, así como entre éstos y sus organismos representativos y recupera la solidaridad y el sentido de unión nacional.

Es necesario crear las condiciones para que se afiancen los valores emergentes de la solidaridad y la tolerancia, recobrando así la confianza en el otro que permitirá desarrollar este movimiento de participación, de modo que signifique una práctica democrática cotidiana.

Las propuestas de participación deben estar necesariamente entrelazadas con la vida cotidiana y los intereses más vitales de cada argentino. Deben estar orientadas a las aspiraciones más importantes y vinculadas con la satisfacción de necesidades 
concretas de modo que cada joven se sienta hacedor de su propia vida y constructor de la nueva sociedad. Hay todavía supervivencias de aquel mundo exterior agresivo que indujo a los argentinos a enclaustrarse en su ámbito privado y a confiar sólo en lo que les era cercano.

Pero tenemos que estar convencidos de que el argentino de hoy quiere trascender ese círculo de lo inmediato. No se contenta con lo que tiene, quiere progresar, ansía encontrar caminos de integración social, busca espacios que le permitan ampliar su vida personal, y está dispuesto a realizar los esfuerzos necesarios para lograrlo.

El concepto de esta democracia participativa que buscamos impulsar, representa una extensión e intensificación del concepto moderno de democracia, y no se contrapone en modo alguno al de democracia formal. Toda democracia es formal, en tanto implica normas y reglas para contener, delimitar y organizar la actividad política y el funcionamiento de las instituciones del Estado y de la sociedad.

Y toda democracia, por definición, implica también la participación de la ciudadanía en las decisiones políticas.

El precepto constitucional, según el cual el pueblo no delibera ni gobierna, sino a través de sus representantes, no excluye, por cierto, otros mecanismos de participación. De lo que se trata, entonces, es de ampliar las estructuras participativas fijadas por la misma Constitución, y dar canales de expresión adecuados a los partidos políticos, las organizaciones sociales, los municipios, las instituciones barriales y vecinales.

Estamos convencidos de que cuanto más una persona participa junto a otras en la acción, con miras a ciertos fines colectivos, tanto más cobra conciencia de esos fines y se siente entonces aún más impulsada a trabajar mancomunadamente para alcanzarlos.

Una ética de la solidaridad:

Cambiar la mentalidad arraigada en nuestra sociedad, eliminar sus componentes de autoritarismo, de intolerancia, de 
egoísmo, de predisposición a la compartimentación sectorial y de ineptitud para el diálogo y el compromiso, constituye una empresa cuyo punto de llegada no puede ser otro que la construcción de una nueva voluntad colectiva.

Desde el momento en que esa empresa se plantea como creación y desarrollo de una sociedad solidaria, contra todos los factores de disgregación que aún perduran entre nosotros, la tarea adquiere una insoslayable y decidida dimensión ética.

Accedemos aquí, entonces, a otro de los pilares del trípode que define los cimientos de nuestra propuesta: una ética de la solidaridad. Desde ese ángulo ético -que no es aislable de los otros y que los contiene- se enunciarán algunas de las condiciones y de los objetivos del proyecto de sociedad hacia el cual apuntamos, esto es, el de una sociedad democrática participativa, solidaria y eficiente.

Desnaturalizada por el utilitarismo individualista clásico, rechazada como mera ideología por los varios mesianismos decimonónicos, la ética ha corrido el riesgo, ya de convertirse en un mero ejercicio escolástico o antropológico, ya de degradarse en un simple recetario catequístico de las "buenas" y "malas" acciones.

Pero desde el momento en que el pensamiento moderno pone al desnudo, tanto los caminos sin salida del egoísmo utilitarista, como los atolladeros de una aprehensión determinista natural de la Historia, la sociedad aparece como lo que realmente es: el producto abierto de una sucesión de proyectos, de decisiones, de opciones.

Así, pues, abriendo las puertas de la elección entre alternativas, el pensamiento y la política moderna recuperan los interrogantes básicos de la ética en tanto hombres y grupos buscan una fundamentación a sus proyectos. ¿Por qué es mejor el orden que la anarquía?, y ¿cuál o cuáles, entre los órdenes políticos, son preferibles? Estas preguntas medulares de la filosofía política comportan una clara dimensión moral, frente a la cual toda concepción mecanicista de lo social no es más que una coartada. 
En muchos aspectos, la sociedad argentina ha sido -y hasta cierto punto continúa siendo- una sociedad fuertemente influida por el egoísmo de sus clases dirigentes. Incluso, un cierto pensamiento individualista cree aún que la armonía social es posible fomentando ese egoísmo. Ese egoísmo ha debilitado la solidaridad social, generando situaciones de desamparo y miedo que nos han hecho particularmente permeables a las pseudosoluciones mesiánicas -populistas y otras-, en las que el individuo aislado busca una instancia exterior en la cual reconocerse y bajo la cual protegerse. El egoísmo ha sido así, caldo de cultivo tanto del autoritarismo pseudoliberal como del mesianismo populista.

Contra esos callejones sin salida, se impone afirmar una ética de la solidaridad, que procure poner de relieve la armonía de la creación, desvirtuada tantas veces. En tal sentido -y esto es fundamental-, una ética de la solidaridad implica que la sociedad sea mirada desde el punto de vista de quien está en desventaja en la distribución de talento y riquezas.

Pero si no queremos incurrir en vacuidad, debemos definir los ejes fundamentales de esa ética. Dicho en términos claros, en los marcos de un proyecto de modernización, la forma que ha de asumir una ética de la solidaridad consistirá en resolver equitativamente el problema de los distintos sectores en su interacción social.

En una sociedad con creciente complejidad, donde chocan múltiples intereses y en la que han caducado los mecanismos corporativos de relación social, es preciso imaginar y construir un sistema de justicia, en la organización democrática de la sociedad y de igualdad, en la búsqueda de la realización personal.

Es aquí donde hay que acudir a la idea del pacto democrático, esto es, de un compromiso que, respetando la autonomía de los actores sociales, defina un marco global compartido dentro del cual los conflictos puedan procesarse, sin desembocar en el caos, y las diferencias coexistan, sin disolverse.

La concepción del pacto aparece en el mundo moderno como el único esquema de referencia que permite conciliar la 
existencia de una pluralidad diferenciada de sujetos sociales con un principio ordenador que intermedie en los movimientos de cooperación necesarios para la convivencia social.

Pero, ¿cómo presentar una versión válida del pacto democrático efectivamente conciliable con una ética de la solidaridad? Para ceñir este problema, basta con evocar la persistente tensión planteada entre libertad e igualdad, está en el centro de las discusiones y de las creencias políticas contemporáneas. Piénsese en la tradición liberal, en el pensamiento social de la Iglesia, en los movimientos obreros y socialistas.

Al respecto, pensamos que para comenzar a superar esa tensión es necesario enriquecer y, por tanto, redefinir la noción tradicional de ciudadano -o de ciudadanía-, reconociendo que ella abarca, además de la igualdad jurídico-política formal, otros muchos aspectos, conectados con el ser y el tener de los hombres, es decir, con la repartición natural de las capacidades y con la repartición social de los recursos.

Es claro, hay una distribución natural desigual. Hay, asimismo, una distribución social e histórica desigual de riquezas, estatus, réditos. Esas desigualdades acarrean consecuencias que son incoherentes o contradictorias con el hecho de reconocer a cada uno como miembro con igual dignidad en el seno de la cooperación social.

Un pacto democrático basado en esa ética de la solidaridad supone la decidida voluntad de que esté sustentado en condiciones que aseguren la mayor justicia social posible y, consecuentemente, reconoce la necesidad de apoyo a los más desfavorecidos.

La modernización.

Dado el proyecto de sociedad aquí propuesto, la modernización que se propugna ha de estar en concordancia con las premisas y condiciones de dicho proyecto.

No se trata de modernizar con arreglo a un criterio exclusivo de eficientismo técnico -aun considerando la dimensión tecnológica de la modernización como fundamental-; se trata 
de poner en marcha un proceso modernizador tal que tienda, progresivamente, a incrementar el bienestar general, de modo que la sociedad en su conjunto pueda beneficiarse de sus frutos.

Una modernización que se piense y se practique pura y exclusivamente como un modo de reducir costos, de preservar competitividad y de acrecentar ganancias es una modernización estrecha en su concepción y, además, socialmente injusta, puesto que deja por completo de lado las consecuencias que los cambios introducidos por ella acarrearán respecto del bienestar de quienes trabajan y de la sociedad en su conjunto.

Aquí se propone una concepción más rica, integral y racional de la modernización que, sin sacrificar los necesarios criterios de la eficiencia. los inserte en el cuadro más amplio de la realidad social global, de las necesidades de los trabajadores, ${ }^{3}$ [de las demandas de los consumidores e incluso de las exigencias de la actividad económica general del país.

Sin duda, esta concepción integral de la modernización, que sólo es pensable en un marco de democracia y de equidad social, planteará dificultades y problemas en ocasión de su implementación efectiva. Se sabe que no siempre es fácil conciliar armoniosamente eficiencia con justicia. No obstante, desde la óptica de una ética como la que aquí se promueve, se ha de mantener que tal es la concepción más válida de la modernización, ya que sólo hay modernización cabal donde hay verdadera democracia y, por lo tanto, donde hay solidaridad.

En rigor, el razonamiento implica postular la propuesta de un proyecto de democracia -como tal opuesto a otros proyectosy de ninguna manera afirma que democracia y modernización estén por fuerza vinculadas históricamente.

3 Debido a que el audio de Radio Nacional Argentina se interrumpe, pero continúa párrafos siguientes, lo que sigue entre corchetes es extraído de la publicación Revista La Ciudad, punto de encuentro. "Para releer: Alfonsín en Parque Norte, 01/12/1985 (3er. Movimiento Histórico)", Concepción Uruguay, Entre Ríos. En https://laciudadrevista.com/para-releeralfonsin-en-parque-norte-01121985-3er-movimiento-historico/. Cada vez que se interrumpa el archivo sonoro, procederemos a colocar esta indicación. 
El "trípode" es un programa, una propuesta para la colectividad, no una ley de la historia. Sólo podrá realizarse si se pone a su servicio una poderosa voluntad colectiva. En política, los términos no son neutrales ni unívocos, deben ser definidos. Ya lo hicimos al precisar nuestra concepción de democracia.

También son varios los significados de modernización. Nosotros la concebimos, taxativamente articulada con la democracia participativa y con la ética de la solidaridad. Toda modernización es un proceso socialmente orientado, surge de una matriz cultural, responde a determinados valores -lo cual significa que rechaza a otros- y se vincula con determinados intereses.

En ese sentido, es históricamente cierto que democracia y modernización no han marchado siempre juntas y que antes y ahora se han planteado proyectos de modernización económica que no se compadecen con una sociedad democrática. Bajo el capitalismo y bajo el socialismo se han dado procesos de modernización autoritaria; los ejemplos son múltiples, y en general se vinculan con ideologías extremadamente liberales que confían en el egoísmo del mercado o con ideologías extremadamente estatistas que confían en la planificación centralizada y compulsiva.

Frente a una modernización que se basa en el refuerzo de los poderes privados, y otra que se basa en el refuerzo de los poderes del Estado, la modernización en democracia y en solidaridad supone reforzar los poderes de la sociedad, autónomamente constituidos.

¿Cuál es el marco de referencia en el que se encuentra colocada de manera predominante, en el mundo contemporáneo, la discusión sobre la modernización?

Parece evidente que el énfasis está colocado en los aspectos económicos y tecnológicos. Es natural que así sea, porque tras un período de crisis de las ideologías, de desideologización de los hábitos políticos, se acumulan los resultados de una revolución tecnológica de una magnitud tal -sólo comparable al producido hace dos siglos por la Revolución Industrial- que, además de su efectividad real como instrumento de cambio de 
la vida cotidiana, ha adquirido el carácter de un mito colectivo potencialmente peligroso, en tanto se constituya al margen de la democracia y de la ética de la solidaridad.

El pensamiento tradicionalista, presentado como mera inversión del anterior, ofrece una respuesta simple al rechazo del progreso que la innovación tecnológica promueve y el refugio en un mundo nostálgico. Pero ni las afirmaciones simples, ni las respuestas simples sirven históricamente; se hace necesario aceptar el desafío de la modernización y a la vez despojarlo de sus peligros autoritarios y de su amoralidad tecnocrática. Por razones particulares, que trataremos de despejar ahora, ese problema es crucial en nuestro presente.

Modernización: El tema de la modernización no es nuevo en la historia social argentina. En rigor, el primer momento clásico de los procesos de modernización -el pasaje de una sociedad tradicional a otra de masas- ya ha sido cubierto entre nosotros hace décadas. Esta modernización ha agotado su capacidad expansiva sin que haya sido reemplazada por otra propuesta de desarrollo. La crisis de las primeras formas de modernización es simultánea con otro proceso de nuestra decadencia, coincide con una verdadera mutación que se está operando en los países centrales.

Esta asincronía entre nuestra crisis y los rápidos procesos de cambio tecnológico que se están dando en el mundo, acentúa el dramatismo del caso argentino y la necesidad de definir urgentemente el paso hacia una nueva modernización.

¿Cuáles deberían ser sus características? Hay, en primer lugar, una dimensión económica y tecnológica. No hay política de modernización que pueda dejar de lado esa dimensión y, en tal sentido, debe constituir un eje definitorio de propuestas para el futuro. Frente a una frontera científica y tecnológica, que en los países centrales se expande a la vez en tantas direcciones y con tal velocidad, está claro que la Argentina no puede quedar como espectadora de avances ajenos y como consumidora pasiva de sus logros. 
Es necesario superar desgastantes antinomias planteadas entre ciencia básica, ciencia aplicada y desarrollo tecnológico. Sin ciencia no habrá más que tecnología escasa o exógena, cuya evolución será frágil y temporaria; sin tecnología, los beneficios producidos por la ciencia para el país carecerán de efecto multiplicador y quedarán limitados a ámbitos cerrados.

El papel de la universidad, crucial para el desarrollo de la investigación científica. solo podrá concretarse acabadamente en el contexto de una modernización global de la sociedad y su aparato productivo, para que sus egresados sean el puente efectivo entre los conocimientos logrados y su aprovechamiento concreto.

Ello implica, tanto la adecuación de programas de estudio y criterios pedagógicos a los avances de la ciencia y la tecnología contemporáneas, como la creación de los cauces indispensables en las actividades económicas a fin de no dilapidar esfuerzos.

No habrá producción moderna sin el aporte de la ciencia ni habrá investigación realmente útil para el país sin centros de actividad, públicos y privados, que estén en condiciones de aplicar sus resultados. La ciencia y la investigación también deberán estudiar y prever los efectos que tendrá sobre la sociedad, la incorporación de las nuevas tecnologías, a fin de aportar los elementos necesarios para potenciar las consecuencias positivas y neutralizar las negativas.

La política de fondo para la ciencia debe asegurar el crecimiento y la vitalidad de la base científica del país en el largo plazo; la política tecnológica, por su parte, debe asegurar una capacidad de decisión autónoma para encarar opciones de distintos grados de complejidad y la capacidad de generar y transferir tecnologías adaptadas a las necesidades e intereses nacionales. Es necesario promover la consolidación de una tradición de desarrollo tecnológico en las unidades productivas, tanto las estatales como las privadas.

Frente a la tradicional política de comprar la tecnología -muchas veces sin tener parámetros para evaluar qué se está comprando-, es necesario impulsar acciones de adaptación, de 
mejora, de perfeccionamiento y de innovaciones, tanto menores como de gran alcance.

Es ya un lugar común decir que se debe poner el énfasis en asimilar y desarrollar autónomamente las tecnologías de punta, la informática, la electrónica y sus aplicaciones, la biotecnología, la petroquímica y el desarrollo de nuevos materiales, Y ya se ha señalado que autonomía no es autarquía. Hay suficiente experiencia internacional para abandonar la idea de un país absolutamente aislado y autosuficiente.

Recalcamos que es esencial no perder de vista esa frontera científico-técnica que se expande, y trabajar para llegar a ocupar posiciones en su línea de avance, las que mejor convengan a nuestro proyecto de modernización estructural. Pero al establecer nuestras prioridades, no podemos dejar de señalar que, en una primera etapa, nuestro bienestar e independencia se seguirán basando en el uso racional e inteligente de recursos tradicionales como la agricultura, la pesca, la minería y las industrias ya establecidas: metalúrgica y bienes de capital, alimentos, química, etcétera.

Mucho se puede avanzar en la necesaria modernización de estos sectores mediante el aporte del sistema científicotécnico con que cuenta nuestro país. Asimismo, se debe procurar que esa carga no recaiga de un modo unilateral en el Estado, sino que llegue a ser también parte de la actividad normal de las empresas privadas, tal como ocurre en otras partes del mundo.

Pero con esto no se agota el debate sobre la modernización, salvo que, como hemos señalado, caigamos en el mito tecnológico.

Las relaciones que deben establecerse entre modernización y justicia social, y entre modernización y democracia pasan a ser cruciales para deslindar este proyecto de los de la izquierda anacrónica, del populismo y del liberalismo económico. Las crisis de los primeros ciclos de modernización han dejado al 
desnudo entre nosotros las falencias con las que ellos se estructuraron en el momento de su expansión] $]^{4}$.

La Argentina creció por agregación y no por síntesis. La modernización y la industrialización fueron así suturando procesos de cambio a medias, incompletos, en los que cada transformación arrastraba una continuidad con lo viejo, sobreagregándose a ello.

De hecho, la sociedad se fue transformando en una suma de agregados sociales que acumulaban demandas sobre el Estado y se organizaban facciosamente para defender sus intereses particulares.

El resultado de esa corporativización creciente fue una sociedad bloqueada y un Estado sobrecargado de presiones particularistas que se expresaba en un "ordenansismo" jurídico cada vez más copioso y paralizante, a la par que sancionaba sucesivos regímenes de privilegio para distintos grupos.

Los costos de funcionamiento de una trama social así organizada sólo podían ser financiados por la inflación que, como veremos, se transformó entre nosotros en la forma perversa de resolución de los conflictos.

En las condiciones, y bajo las necesidades de hoy, encarar una nueva modernización como salida para la prolongada crisis de la anterior, implica crear, en lugar de esa sociedad bloqueada con la que culminó el ciclo anterior, una sociedad flexible.

¿Qué entendemos por flexibilidad de la sociedad? Obviamente, no se trata de propugnar la disolución de todos los elementos de orden y disciplina social, consensualmente aceptados. La flexibilidad no es la anomia, el rechazo de los valores que constituyen la estructura de toda convivencia civilizada. Pero si el respeto a las normas es indispensable para sostener la vida en común, un exceso de rigidez en las mismas puede acarrear la presencia de frenos para la innovación.

4 A partir de aquí continúa el archivo sonoro de Radio Nacional Argentina y la desgrabación del mismo. 
Las sociedades tratan de buscar el equilibrio entre la continuidad y el cambio. Tal como lo postulamos, la flexibilidad significa posibilidad de aperturas a nuevas fronteras. Implica, además, consolidar en todas las dimensiones el rasgo más elocuente de la modernización, que es la capacidad de elección de los hombres frente a la obediencia ciega ante la prescripción.

Dadas las características con las que se dio nuestro crecimiento, tenemos a nuestras espaldas bastiones de derechos adquiridos, nichos de privilegios que se fueron sobre agregando a nuestra legislación, haciendo que nuestro estado social no fuera el producto de una universalización de derechos, sino la sumatoria de derechos particulares que generaban una ineficiencia generalizada.

La manera en que se ha organizado entre nosotros la previsión social y el derecho a la salud -dos conquistas fundamentales de la sociedad contemporánea-, son un ejemplo palmario de esta dilapidación de recursos humanos y materiales.

En el caso de nuestra economía, esta rigidez es también un elocuente testimonio de nuestros fracasos. ¿Cuántos recursos se despilfarraron por carencia de una mayor flexibilización de las normas de trabajo, de producción y de gestión?

$\mathrm{Y}$ esta rigidez paralizante, abarca tanto a los sectores público como al privado. porque la sociedad es una y sus vicios de crecimiento han empapado a todos los sectores.

Al plantear esta exigencia de flexibilidad en todos los órdenes como una característica central de la modernización en la Argentina, buscamos, además, desplazar la discusión de los ejes en los que habitualmente se la coloca. Nos referimos a una homologación simplista entre modernización y cambio tecnológico.

La incorporación de tecnologías de punta no tiene efectos mágicos, no moderniza automáticamente a una sociedad y, menos aún, garantiza que la modernización sea compatible con la participación y con la solidaridad. Transformar en eficiente una sociedad quiere decir, sobre todo y antes que nada, mejorar la calidad de la vida de los hombres. 
En ese sentido, el proceso procura modernizar no sólo la economía, sino también las relaciones sociales y la gestión del Estado, dotando a los ciudadanos de cuotas crecientes de responsabilidad, a fin de asociarlos a una empresa común.

La modernización no es un tema exclusivo de las empresas, es toda la sociedad la que debe emprender esa tarea y con ella la nación, redefiniendo incluso su lugar en el mundo. Modernizar es, también, encontrar un estilo de gobierno que mejore la gestión del Estado y que plantee, sobre otras bases, la relación entre éste y los ciudadanos.

Este debate acerca del papel del Estado y de las relaciones entre éste y la sociedad -que comienza por distinguir una dimensión de lo público como diferente de lo privado y de lo estatal- deberá ser tomado por la comunidad como uno de los temas claves del momento.

Como tal, debería ser considerado con mayor seriedad que lo que se hace hasta ahora, cuando el campo parece sólo ocupado por los privatistas y por los estatistas a ultranza.

Consideramos esencial revertir el proceso de centralización, que se ha venido produciendo desde hace décadas en la administración del Estado, no sólo para alcanzar un objetivo de mayor eficiencia, sino también, y fundamentalmente, para asegurar a la población, posibilidades más amplias de participación.

Existe una relación inversamente proporcional entre centralización y participación. Una gestión estatal muy concentrada implica confiar el manejo de la cosa pública a un núcleo burocratizado de la población, que desarrolla como tal, conductas sujetas en mayor medida a sus propios intereses corporativos, que al interés general de la población.

Descentralizar el funcionamiento del Estado significa al mismo tiempo abrirlo a formas de participación que serán tanto más consistentes cuanto mayor sea su grado de desconcentración.

Descentralizar es un movimiento no sólo centrífugo, sino también descendente, que baja la administración estatal a niveles 
que pueden reservar a las organizaciones sociales intermedias, un papel impensable en un sistema de alta concentración.

Si al modernizar queremos mantener vigente la solidaridad y la participación, y este -como hemos visto- es nuestro programa para la Argentina que quiere entrar al siglo XXI hace falta convocar a toda la sociedad, a los ciudadanos y a las organizaciones, para poner en marcha una discusión franca y constructiva que permita superar los bloques que nos condenaron a la decadencia.

La desburocratización, que busca liberar fuerzas contenidas por una cultura corporativa, no implica necesariamente privatización en el sentido vulgar de los reclamos de los ultraliberales. Si rechazamos al estatismo agobiante que frena la iniciativa y la capacidad de innovación, no ignoramos que la rigidez y la defensa de bastiones privilegiados, no ha sido sólo patrimonio del Estado, sino también de la empresa privada.

Se trata de un problema de toda la sociedad argentina, y no meramente de una parte de esa sociedad como es el Estado.

Las dificultades que debemos enfrentar.

La violencia en nuestra cultura política.

Después de muchas décadas, la sociedad argentina ha logrado crear las condiciones necesarias para poner en marcha formas de organización política basadas en la juridicidad.

Desde 1930 en adelante, el sistema político se fue constituyendo alrededor de la violencia y de la ajuridicidad.

Primero fue la violencia del golpe militar interrumpiendo un doloroso y largo proceso de construcción democrática en el cual se habían comprometido las élites más lúcidas del país y al que habían aportado su voluntad las grandes masas populares.

Luego, en los aciagos años treinta, fue la violencia del fraude, desnaturalizando ese acto trascendental de la democracia que es la elección por los ciudadanos de sus representantes.

Más tarde, recuperada la posibilidad del voto popular, y reabierto los cauces para una ampliación de la democracia a través de la implantación de una ciudadanía social que integraba definitivamente a las grandes masas a la sociedad nacional, la 
violencia, sin embargo, no desapareció del sistema político y llegó a asumir la forma de un partido hegemónico que dificultaba la competencia por el poder.

Por fin, superada esa experiencia, la violencia política se expresó en la recurrencia de las intervenciones militares, que derrocaron en las últimas tres décadas a todos los gobiernos surgidos de comicios.

En el período que nace a principios de los años '70, esta ajuridicidad, que había marcado la vida de varias generaciones de argentinos, ocupó la totalidad del espacio institucional y se derramó hacia la sociedad entera. Vivimos entonces -y recién estamos saliendo de ello- el horror de una comunidad nacional que pareció perder los hábitos de la convivencia civilizada, sometida al pánico engendrado por los violentos de todo signo.

En octubre de 1983, esta sociedad, aún aturdida por el dolor, votó masivamente por la vida contra la muerte y reafirmó, el último 3 de noviembre, la voluntad de no dejarse arrebatar la esperanza de una existencia en paz.

Somos conscientes de que estamos poniendo los cimientos para una reconstrucción del orden civilizado en la Argentina.

Sabemos, también, que la tarea no es ni será sencilla, porque los hábitos perversos no se derrotan fácilmente, y porque quedan aún nostálgicos del terror que harán lo posible para que retornen los tiempos oscuros que les sirvieron para medrar.

Contra todos los obstáculos, la tarea fundacional de la democracia -que no es de un gobierno ni de un partido, sino que es responsabilidad de todo el pueblo- habrá de persistir tenazmente, hasta borrar para siempre los componentes autoritarios que durante más de cincuenta años enfermaron a nuestra sociedad y envilecieron a sus instituciones.

Vamos duramente, pero con la confianza de quienes están construyendo sólidas bases, hacia una experiencia democrática continua y afianzada.

La ajuridicidad montada sobre la violencia destruye las instituciones. Todas las instituciones: en primer lugar, las políticas, 
pero también las económicas, las sociales, las culturales. Al transformarse en una estructura permanente, en el aparente horizonte al que todos deben mirar, penetra hondamente en la vida cotidiana, empapa los comportamientos, transforma a la inseguridad en costumbre y al egoísmo en rutina. Cuando se incita a una comunidad a vivir en los marcos del "sálvese quien pueda", se está destruyendo la dimensión ética de la vida.

La inflación como sistema de una sociedad facciosa.

Uno de los síntomas más claros de la inmoralidad argentina de las últimas décadas estuvo expresado por la persistente presencia del flagelo inflacionario.

Al encarar frontalmente su erradicación tuvimos clara conciencia de que las medidas adoptadas eran algo más que los elementos de una reforma económica. Ellas implicaban poner las bases para una reforma política y, más profundamente aún, para una reforma de nuestras costumbres, para una reformulación de nuestra moral colectiva.

La inflación es la otra cara de la violencia y de la anomia, el reverso de una misma medalla, la de la decadencia social. La sociedad argentina fue llevada a adquirir los rasgos de una sociedad facciosa, la depreciación de la moneda implicaba simultáneamente la depreciación de todos los valores de la solidaridad colectiva.

Los necesarios conflictos que recorren la trama de toda sociedad moderna se resolvían de manera a la vez ilusoria y perversa, mediante los mecanismos de alivio transitorio y sólo nominal que la creación ficticia de papel moneda procuraba. Los comportamientos defensivos y las actitudes corporativas, especulativas, facciosas, de los grupos sociales encontraban su realimento en la cultura de la inflación.

Ningún compromiso colectivo se hace posible en esas condiciones de exacerbación del egoísmo. Y la democracia es, por definición, un compromiso de voluntades racionales que eligen decidir sobre su destino.

En oportunidad de ponerse en marcha la reforma económica señalamos que, "si el problema económico no es resuelto, 
la vida política de la nación correrá serios riesgos”. Es que, corroída en sus bases éticas, la vida política bajo la cultura de la inflación, abre las puertas a la indiferencia ciudadana o a las falsas soluciones mesiánicas.

Crisis e innovación.

Sabemos que estamos viviendo una época de transición. Por voluntad de la mayoría, un ciclo ha terminado. Un ciclo largo que hemos definido reiteradamente como de decadencia económica, institucional y moral.

Lo que nace, y lo que muere, se entrecruzan; la innovación coincide con la crisis en un movimiento todavía mezclado. La crisis de la que intentamos salir es, seguramente, la más grave y profunda de este siglo, y la innovación que buscamos implantar es la de la democracia como forma política pero también como forma de vida, como sistema y como estilo de convivencia entre los hombres.

No habremos triunfado hasta que estas dos dimensiones se hayan hecho una, hasta que las rutinas del autoritarismo que marcó nuestras vidas sean transformadas por las rutinas de la democracia. En una palabra, hasta que ésta no descanse solamente en las formas institucionales, sino que penetre en la íntima conciencia de cada argentino.

En este sentido, la crisis no es sólo un obstáculo, la comprobación de la enfermedad en un cuerpo sano (un bloqueo económico y social para una empresa de modernización). En su remoto origen lingüístico, "crisis" significa también discriminar y decidir.

Debemos rescatar el momento productivo de la crisis como estímulo para la capacidad de elegir entre alternativas. Más aún, es porque los hombres y los pueblos son capaces de erigir proyectos alternativos a las situaciones de injusticia y de decadencia que las crisis estallan. Ellas no son un fenómeno de la naturaleza, sino una producción de la historia.

Las crisis llevan en sí la potencialidad de la innovación. Marcan los momentos de emergencia de nuevas demandas, de 
nuevos proyectos de vida, de nuevos actores sociales y de recuperación de la iniciativa y de la capacidad de invención colectiva.

Es la elección por la alternativa de la democracia lo que provocó la crisis del autoritarismo. Pero lo hemos dicho ya, la democracia remite a dos niveles: es, por un lado, un procedimiento ciudadano sobre el que se basa un orden político. Y es, por el otro, un espacio, el único legítimo, para imponer en él proyectos de transformación social.

Ambas dimensiones, aunque no estén históricamente fusionadas, deben tender a complementarse. Si la democracia no es capaz de amparar procesos transformadores, procesos que en la Argentina de hoy se resumen en el imperativo de modernizar al país sin abdicar de una ética de la solidaridad, fracasará también, inevitablemente, como procedimiento, como régimen político.

La estrategia.

Esas son nuestras dificultades. Para abordarlas, resulta imprescindible elaborar una voluntad democrática moderna, que esté a la altura de la necesidad de innovación formal y sustantiva que reclaman los tiempos.

Por cierto, que no partimos de cero. Si bien es verdad que los grandes sistemas ideológicos están en crisis, es verdad también que esa crisis libera elementos parciales que aceptan una recomposición en un nuevo consenso integrador.

Pensamos en una síntesis que recupere lo mejor de las grandes tradiciones políticas argentinas y que, al hacerlo, sea capaz de constituir una nueva voluntad colectiva que sea algo más que una suma de programas parciales.

Esta voluntad democrática colectiva no implica uniformidad; significa un piso común de creencias capaces de contener dentro de sí al pluralismo y a la diversidad.

$\mathrm{Al}$ transformar diferentes problemas planteados por variadas ideologías en temas comunes, una nueva voluntad democrática se consolida porque es capaz de penetrar, como un lenguaje compartido, en la mayoría de las propuestas políticas y sociales, respetando su particularidad. 
En esta etapa de transición, en este momento fundacional, parece no sólo legítimo, sino también indispensable recuperar y resignificar esos valores heredados.

Pero es también cierto, sin embargo, que un consenso democrático moderno no puede contentarse con rearticular contenidos provenientes de concepciones anteriores. Debe también incorporar otros, surgidos más recientemente, producto de nuestra contemporaneidad.

Las sociedades modernas asisten a procesos de creciente diferenciación y complejidad sociales. Emergen nuevos sujetos, portadores de nuevas demandas, de nuevos temas de convocatoria. Ellos también deberán tener su lugar en el emprendimiento común.

La convocatoria.

Desde hace dos años, luego de un largo lapso de desencuentros y frustraciones, la Argentina transita decididamente los caminos de la democracia. Ha costado acceder a ella, como lo muestran los padecimientos y obstáculos que hemos debido sobrellevar para alcanzarla, y costará sin duda afianzarla definitivamente, ya que la hemos conquistado en medio de terribles limitaciones y problemas de orden económico, social y políticos. Algunos de ellos heredados de nuestra historia reciente, otros provenientes del proceso global de crisis y de transformaciones profundas que vive el mundo en la hora actual.

La democracia argentina no es débil, en la medida en que cuenta con medios y voluntades para sostenerse. Pero tampoco es aún una democracia consolidada, puesto que tanto esos medios, como sobre todo esas voluntades, no han logrado todavía que la adhesión espontánea del ciudadano argentino a la democracia se traduzca en la interiorización de hábitos de convivencia política que hagan literalmente inconcebible cualquier sueño de involución autoritaria.

He aquí una tarea que debe ser asumida, y para la cual son necesarias iniciativas específicas. Dicho esto, sin embargo, es preciso tener en cuenta que la consolidación de la democracia sólo define el marco, fundamental, por cierto, en el interior del cual un conjunto de determinados objetivos se encuadra. 
Esos objetivos han sido motivo de esta exposición y se resume en el logro de una sociedad moderna, participativa y solidaria. También en este caso, determinadas iniciativas deben ser puestas en marcha.

La historia argentina, en casi todo lo que va del siglo XX, es la de un país cuyas relaciones sociales no han estado sujetas, como lo dijimos, a un pacto de convivencia.

Las múltiples luchas que precedieron el acceso al gobierno del radicalismo, la violenta restauración conservadora del '30, auspiciada por previos conflictos y perturbaciones del orden social, la irrupción del peronismo como fórmula frontalmente opuesta a las expresiones políticas preexistentes, y la posterior revancha antiperonista, constituyeron sucesivas manifestaciones de una misma indisponibilidad para convivir en un marco globalmente compartido de normas, valores e instituciones.

Sobre ese trasfondo histórico, caracterizado por la ausencia de un universo normativo globalmente reconocido e institucionalizado, sólo hubo lugar -salvo breves excepciones- para una ficción de democracia, o bien, como ocurrió las más de las veces, para la instauración abierta del autoritarismo.

En este sentido, cabría decir que la democracia no debe ser restaurada, sino construida en nuestro país. Ahora bien, cuando hablamos de construcción de la democracia no nos estamos refiriendo a una simple abstracción; nos estamos refiriendo a la fundación de un sistema político que será estable en la medida en que se traduzca en la adopción de rutinas democráticas asumidas y practicadas por el conjunto de la ciudadanía.

Las normas constitutivas de la democracia presuponen y promueven el pluralismo y, por lo tanto, la pacífica controversia de propuestas y proyectos acerca del país que anhelamos.

Los objetivos antes enunciados, cuya síntesis cabe en la fórmula de una sociedad moderna, participativa y éticamente solidaria, constituye, en ese sentido, uno de tales proyectos.

Tenemos, sin embargo, la convicción de que no se trata de un proyecto más; de que, sin perjuicio de ser discutido, corregido, 
perfeccionado, posee una capacidad convocante que excede, por sus virtualidades propias, los puntos de vista particulares de un sector, de una corporación e incluso de una agrupación partidaria. Sin duda, esa capacidad ha de ponerse a prueba.

Tal es, al fin y al cabo, el principal motivo de esta convocatoria. De ser escuchada, habrá de afirmarse bajo la forma de coincidencia de fuerzas políticas y de concertaciones de las organizaciones sociales.

En sus términos más sustantivos, la convocatoria implica una propuesta de reformas específicas a nivel económico, político, social, cultural e institucional. Tal propuesta, que tiene como guía el objetivo fundamental, ya enunciado, una sociedad moderna, participativa y solidaria, deberá, como es natural, ser precisada y desarrollada oportunamente con el concurso de cuantos quieran sumarse al proyecto.

Al partido político más viejo de la Argentina, la historia le abre hoy la posibilidad de ser la fuerza aglutinante para la construcción del país nuevo, del país moderno.

La Unión Cívica Radical está llamada a ser el partido de la convocatoria para el futuro y esto no es fruto de una casualidad. Su primera gran función histórica fue la de instaurar la democracia concreta en los marcos que las fuerzas organizadoras del país habían delineado a partir de mediados del siglo pasado, pero que se habían limitado en la práctica a un restringido sector social.

El radicalismo completó la primera modernización del país con la incorporación de la ciudadanía a la vida política. Su convocatoria no se redujo, sin embargo, a la mera aplicación de las reglas constitucionales en plenitud y a la vigencia del sufragio universal y secreto.

Una concepción ética de la política y un profundo sentido de la justicia social se sumaron a la propuesta democrática, en términos no excluyentes de ningún sector y, aparentemente, desligados de las grandes líneas ideológicas que desde hacía dos siglos canalizaban las inquietudes sociales y políticas de los países de Occidente. 
Por cierto, que el radicalismo era una fuerza renovadora y opuesta al conservadorismo, pero no se definió como liberal o socialista, ni tendió a reflejar algunos de los matices intermedios de estas dos opuestas posiciones. Fue, en su modo de actuar, un partido de síntesis, un partido de síntesis nacional donde las reivindicaciones y principios de la libertad, el progreso y la solidaridad social encontraron un cauce abierto.

Por ello recibió frecuentes críticas de los partidos dogmáticos y se le imputó no pocas veces vaguedad ideológica y falta de rigor teórico.

La ironía de la historia ha permitido que esa supuesta ambigüedad sea hoy una de sus mayores riquezas, pues si algo caracterizó al radicalismo en su casi un siglo de existencia es el sentido ético de la política y su adscripción a ultranza al sistema democrático.

Estos dos valores constituyen el punto de arranque ahora de quienes intentan en el mundo contemporáneo, desde la perspectiva de las grandes corrientes políticas históricas, superar las dicotomías que tuvieron sentido o funcionalidad en el pasado pero que ya no se corresponden con los profundos cambios sociales y económicos de la "Segunda Revolución Industrial".

Valores que eran defendidos por liberales o socialistas, y las diversas posiciones intermedias, sin excluir al conservadorismo lúcido y al social-cristianismo, quedaron incorporados a la cultura, a la práctica política y a las instituciones políticas de la mayor parte de Occidente.

Las involuciones totalitarias fueron ${ }^{5}$ [superadas en esa área del mundo luego de la Segunda Guerra Mundial, en un proceso que arrancó de la derrota del nazi fascismo, y que culminó con el derrumbe de los regímenes autoritarios en España y Portugal, y el fracaso de la aventura de los coroneles griegos.

En América Latina, cuyas naciones surgieron a la vida independiente bajo la inspiración de las ideas democráticas y

5 Se interrumpe el archivo sonoro del discurso. 
progresistas, la amenaza autoritaria continúa aún presente, $]^{6}$ pero en los últimos años se está desarrollando un proceso generalizado de democratización. Nuestros pueblos son conscientes, cada vez más, de que ni el desarrollo económico ni la democracia pueden ser el privilegio de algunos pocos pueblos elegidos.

El radicalismo argentino debe provocar la síntesis, suscitar la modernidad, abrir el futuro. Los valores y las metodologías políticas rescatables, y todavía vigentes del pasado, tanto internacional como nacional, deben encontrar en nuestro partido una síntesis armoniosa y superadora, en consonancia con las nuevas exigencias y los nuevos problemas que plantea la humanidad del futuro.

El radicalismo argentino debe sumarse con su aporte a esa búsqueda colectiva de la humanidad para delinear los marcos éticos, políticos y organizativos de su futuro. Debe quedar bien en claro que el rechazo del dogmatismo y de las concepciones mecanicistas y deterministas decimonónicas no abre paso a la vaguedad, sino a la concreción, a la racionalidad y a la experimentación consciente de nuevas fórmulas de convivencia entre los hombres.

En virtud de su tradicional rechazo a las concepciones dogmáticas y sectarias, el radicalismo está en condiciones óptimas para convertirse en el instrumento político y social capaz de asumir y encarnar, con flexibilidad, las exigencias de la sociedad en transformación, de la sociedad que marcha hacia una nueva etapa productiva y organizativa.

Esta flexibilidad no se contrapone al rigor, sino que lo exige, pero es el rigor de los principios de la investigación, de la búsqueda racionalmente orientada, del estudio abierto y valiente.

Pero, además, debemos facilitar el surgimiento de las nuevas ideas, de los nuevos estilos y de las nuevas propuestas que la sociedad argentina necesita para orientar su marcha al futuro, a fin de que se incorporen a la empresa común todos aquellos

6 Continúa el archivo sonoro y su desgrabación. 
argentinos que sientan y comprendan que ha comenzado un nuevo ciclo de nuestra historia y de la historia de la Humanidad. Nuestra propuesta de modernización implica la integración de todo el pueblo, la sociedad que construye su futuro.

Sin solidaridad no se construye ninguna sociedad estable y el primer deber que nos impone la ética de la solidaridad es incorporar al trabajo común a todos aquellos que, sin renegar de su historia, se sientan convocados por un proyecto como el que hemos definido.

Pensamos, en primer término, en quienes fueron condenados por políticas injustas a la miseria y a la marginalidad. Pensamos, también, en las jóvenes generaciones que han sufrido el enclaustramiento de una educación autoritaria y la falta de oportunidades y se integran hoy a la vida política con su impulso decidido y su energía vital dispuestos a construir un nuevo mundo.

Pensamos además en quienes fueron desplazados de la vida política efectiva por la marcha de la historia, herederos de los ideales y ambiciones que guiaron a buena parte de los hombres que en las últimas décadas del siglo pasado comenzaron la edificación de la Argentina moderna. En quienes enaltecieron hasta el límite, el valor de la libertad como el más preciado por encima de cualquier doctrinarismo económico.

En quienes son herederos de la acción ejemplar del socialismo humano, democrático y ético. En quienes buscaron conjugar su creencia religiosa con la construcción de un mundo inmediato, mejor para los hombres y que no han logrado incorporar ese noble ideal a la práctica política concreta de vastos sectores sociales.

En quienes comprendieron que no hay país posible sin desarrollo y entienden la exigencia ineludible de la ética política y del método democrático. En quienes se desprendieron del viejo tronco radical en busca de marchas más veloces.

En quienes procuran una vía efectiva para terminar con la injusta división del país entre un centro relativamente próspero y un interior relegado, acudiendo a mecanismos locales. 
En quienes fueron protagonistas de una experiencia histórica donde la justicia social conmovió como proyecto a nuestra sociedad y vean en la democracia su necesario sostén.

A todos ellos convocamos hoy para que, en pluralidad de ideas y de propuestas, pero en comunidad de aspiraciones y, de ser posible, en una acción conjunta y en un ámbito común, construyamos el país del futuro.

Una convocatoria que, además, comprende a ese vasto conjunto de instituciones, comunidades y organizaciones a través de las cuales se expresa la riqueza espiritual y la voluntad de compromiso y participación de la sociedad, tanto aquellas cuya presencia se remonta a los orígenes de la Patria como a las que han ido surgiendo como respuesta a las exigencias de este tiempo o al compás del dinámico crecimiento social.

Ya ha terminado en el mundo la era de las convicciones absolutas del siglo pasado, la era de los mesianismos y de los historicismos fáciles. El futuro no está predeterminado ni es un papel vacío donde podemos diseñar en forma absoluta nuestra voluntad.

Venimos de un pasado y a partir de él podemos poner cauces racionales al porvenir sin renegar de nuestra herencia, pero sin esclavizarnos a ella. Ella nos pone límites, pero desde esos límites no hay un sólo camino.

Elijamos el de la libertad, la solidaridad y el de la tarea conjunta para afianzar la unión nacional. Ya pasó la Era en que se pudo llegar a creer que la felicidad del género humano estaba a la vuelta de un episodio absoluto, violento, definitivo, que al otro día inauguraría la vida nueva.

La revolución no es eso ni lo ha sido nunca. Revolución es una etiqueta que los historiadores ponen al cabo de siglos a un proceso prolongado y complejo de transformación.

Pero también se terminó la época de las pequeñas reformas, de la ilusión de que con correcciones mínimas se podía cambiar el rumbo de una sociedad que, como la nuestra, fue empujada paulatinamente al desastre. 
No hablemos ya de reforma ni de revolución, discusión anacrónica. Situémonos, en cambio, en el camino acertado de la transformación racional y eficaz.

Nuestro país debe emerger de su prolongada crisis con vigor; y este vigor encontrará su alimento en la decisión de participar de todos los componentes de la sociedad, los responsables de interpretar y representar las necesidades y aspiraciones de los distintos sectores sociales, deben asumir -con firmeza y vocación de servicio- esta exigencia

Debemos aprender a unirnos y a sumar el trabajo de cada uno con el del otro y crear así la transformación y lo nuevo. Es la unión de lo que cada uno de nosotros produce desde su lugar. El trabajo político irradia, y debe llegar con este nuevo espíritu de construcción, a todos los argentinos. Estemos dispuestos a marchar juntos. Debemos lograr la unión de lo que está desunido.

Debe tratarse de una disposición, de una voluntad, pero también de un compromiso para alcanzar la concreción de las ideas en la vida real de las personas.

En cuanto a nosotros, los radicales, debemos comprender que es necesario estar a la altura de esta misión, poner al servicio de las demandas y urgencias del país nuestra fuerza histórica, seguros de que al hacerlo comenzamos a solucionar esas demandas y esas urgencias y evitamos quedar cautivos de los bolsones de la Argentina vieja.

Despojados de toda arrogancia y de todo prejuicio, trabajemos, estudiemos y preparemos junto a nuestros compatriotas el país nuevo, el país del futuro.

[Aplausos y ovaciones prolongados] 